\title{
Correction to: Supply Chain Fragmentation and the Global Trade Elasticity: A New Accounting Framework
}

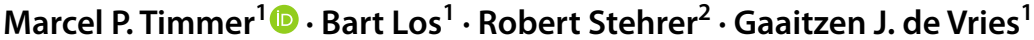 \\ Published online: 30 April 2021 \\ (c) International Monetary Fund 2021
}

\section{Correction to: IMF Economic Review (2021) https://doi.org/10.1057/s41308-021-00134-8}

The original version of this paper was inadvertently published with an incorrect affiliation for the author Robert Stehrer.

The correct affiliation is:

(1) The Vienna Institute for International Economic Studies - wiiw, Rahlgasse 3, A-1060 Vienna, Austria

(2) The statement regarding the supplementary information was not given correctly and the supplementary material was not uploaded on SpringerLink.

The original article has been corrected. We apologise for any inconvenience caused to our readers.

Publisher's Note Springer Nature remains neutral with regard to jurisdictional claims in published maps and institutional affiliations.

The original article can be found online at https://doi.org/10.1057/s41308-021-00134-8.

Marcel P. Timmer

m.p.timmer@rug.nl

1 Faculty of Economics and Business, University of Groningen, P.O. Box 800, 9700 AV Groningen, The Netherlands

2 The Vienna Institute for International Economic Studies - wiiw, Rahlgasse 3, 1060 Vienna, Austria 